\title{
An Examination of Factors That Impact the Retention of Online Students at a For-profit University
}

\author{
Chris Sorensen and Judy Donovan \\ Ashford University
}

\begin{abstract}
Online learning has continued to grow in recent years. However, retaining students in online courses and programs has posed a challenge. Whether the university is public, private, offers both face-to-face and online programs, or is $100 \%$ online, retaining students in online programs can be an issue. This study reflects the widespread desire at a large online for-profit university to improve student retention rates. The goal of the research was to provide further insight into why students may decide to drop out of online programs. Participants consisted of former undergraduate students at the university in the College of Education who dropped out without providing a specific reason for doing so. The study used a non-experimental mixed methods approach collecting data from university databases, an online survey, interviews, and classroom walk-throughs. Data analysis employed techniques such as frequency calculations, a MANOVA, and qualitative content analysis. Results from the MANOVA revealed statistically significant results when examining student Grade Point Average and last course grade. Furthermore, data collected from the online survey, interviews, and classroom walk-throughs revealed common reasons for why students may drop out of online programs.
\end{abstract}

Keywords: Online learning; higher education; for-profit colleges and universities; student retention; adult learners; undergraduate

Sorensen, C. \& Donovan, J. (2017). An examination of factors that impact the retention of online students at a for-profit university. Online Learning, 21(3), 206-221. doi:

10.24059/olj.v21i3.935

\section{Introduction}

Over the years, online learning has become a widely accepted and sought out modality by students. We have seen an increase in the number of online universities available as well as more online options for students at traditional universities. Despite the popularity and growing demand for online programs, retaining students in such programs has been problematic. Currently, online universities are scrutinized for having lower retention rates as compared to their more traditional counterparts. This study focuses on an online university within the for-profit sector. In general, the average retention rate for for-profit undergraduate programs is $46.2 \%$ (National Student Clearinghouse Research Center, 2014). The overall undergraduate retention rate at the university examined in this study is $38.9 \%$. In contrast, online programs in traditional public and private universities have retention rates of $68.2 \%$ (public) and $72.9 \%$ (private) (National Student Clearinghouse Research Center, 2014).

The purpose of this study was to provide further insight into why students may decide to drop out of online programs, with a specific goal of identifying potential factors that might 
influence a student's decision to drop out. At the university in question, an attempt to contact students and find out why they have discontinued their studies was made. Results from a 2014 withdrawal survey at the university identified the following as common reasons for students' discontinuing their studies: personal or family emergencies, needing a break from school, financial burdens from needing to retake course, changes in personal financial situation, and lack of internet access. Unfortunately, these reasons only reflect approximately $29 \%$ of the students who dropped out. The other $71 \%$ of students who dropped out did not complete the survey. These students are categorized as "Missing in Action" (MIA). The research presented here focuses on these MIA students.

To improve retention rates, a better understanding as to why students drop out of online education is needed. As some researchers suggest, dropping out is a process rather than an event and as a result, it may be caused by a combination of factors (Mansfield, O'Leary, \& Webb, 2011). If it can be better understood why students drop out, attempts to intervene to help students overcome a hurdle, possibly anticipate which students may be at risk, and offer additional support can be implemented.

\section{Literature Review}

Online learning in higher education continues to grow faster than on-campus courses, but overall online programs struggle with a lower retention rate (Brown, Keppell, Hughes, Hard, \& Smith, 2013). "Dropout rates from e-learning courses were documented around $25 \%-40 \%$ as compared to $10 \%-20 \%$ in on-campus courses" (Levy, 2004, p.186). In 2014, it was reported that of all first-time, full-time students who entered a bachelor's program in 2006, 59\% had completed the degree in 2012 (The National Student Clearinghouse Research Center, 2014).

Improving student retention rates has been an issue of interest to higher education for many years. Efforts to identify factors or variables that influence students' decision to leave college are ongoing. O'Keefe (2013) identifies such at-risk factors as mental health and disability issues, first year and first-generation college students, part-time as compared to full-time students, socioeconomic status, and ethnicity. Boles, Cass, Levin, Schroeder, and Smith (2010) believe the success of their online undergraduate program is attributable to the higher average student age of 34. Another study found male students are more likely to drop out than female students (Levy, 2004).

Other correlations have been reported in the research. It has been reported that students' sense of belonging to a community, engagement, and interactions with faculty are all related to retention (Lee \& Choi, 2011). Where students are in terms of program completion has been correlated to retention, as well as student status (lower level or upper level) (Levy, 2004). Boles et al. (2010) believe small class sizes of 25 students or less can contribute to higher retention rates. In addition, factors such as goal commitment, social integration, and academic integration have been identified as correlating to retention, as well as perception of outside factors, intrinsic motivation, and students' relationships with their instructors (Mansfield et al., 2011).

Lee \& Choi (2011) examined ten years of research targeting retention in online courses. Through coding of 35 empirical studies, the researchers identified almost 70 "dropout factors," or reasons why students discontinued taking online courses. They sorted and combined these into three groups. 
1. Student factors include academic background, relevant experience, skills, and psychological attributes.

2. Course/program factors include course design, instructional support, and interactions.

3. Environmental factors include work commitment and supportive environment.

While some factors surfaced in the research findings more than others, Lee and Choi (2011) point out that the presence of one impacting factor is not enough to cause a student to desist in a course. Factors are inter-dependent, and it is the "interaction of numerous factors that eventually lead to a student to complete or not complete a course" (Lee \& Choi, 2011). This is further supported by Mansfield et al. (2011) who describe dropping out as a process that occurs over time.

A final point is that retention can be difficult to measure or define. Mansfield et al. (2011) point out that accurate retention rates need to identify students who enroll to complete a course or two, but never intended to complete a degree program. Busy students might choose to drop a course for the present, but plan to re-enroll when things slow down, or drop because they want to take the course with another professor (Levy, 2004). Different ways of measuring and defining retention also attempts to compare different institutions' retention rates.

Student retention is vital for the well-being of students, programs, institutions, and even society. Current research appears to be moving away from trying to identify potential dropouts by factors such as demographics, or program of study, instead realizing that each student, program and institution is unique (Willging \& Johnson, 2009). Research shows that demographic factors such as age, gender, Grade Point Average (GPA), hours worked, etc. may not significantly differ between students who dropped out and those who persisted (Levy, 2004). As retention is still an issue, successful ways of measuring and improving student retention will continue to be sought. The research presented here aims to offer additional insight into the question: What factors may influence a student's decision to drop out of an online for-profit academic program?

\section{Method}

This research project utilized a non-experimental mixed-methods research design. This design was most appropriate as there were no interventions or manipulations and several data collection techniques were used. The research was investigative and exploratory in nature.

\section{Population and Sampling}

The undergraduate student population in the College of Education (COE) at the university in question consists of $70 \%$ female and $30 \%$ male students. Sixty-three percent of the students indicated being employed. In terms of race, $41 \%$ are Caucasian, $41 \%$ African American, and 18\% Asian, Hispanic, Mixed, or did not indicate race. Finally, 43\% are first-time college students (Nettles, 2015). This study sampled from this general population and examined former COE online undergraduate students who dropped out during the 2013-2014 academic year and did not provide a specific reason for why they dropped out. The initial sample consisted of 396 students. Two sampling techniques were used based on the mixed methods nature of the study. First, non-random convenience sampling was used which focused on identifying students who dropped out without providing specific reasons for doing so at the University. The convenience sampling was followed by random sampling from the group of 396 students during one of the stages of data collection. 


\section{Data Collection and Analysis}

Data was collected via several methods and both quantitative and qualitative analysis techniques were employed. It is believed that by using a mixed-methods approach to the data collection, a more comprehensive picture of student retention can be created (Green, Caracelli, \& Graham, 1989). Specifically, data was collected from University databases, an online survey, interviews, and classroom walk-throughs. Data analysis consisted of frequency calculations, a MANOVA, and content analysis. The following summarizes the steps that were carried out to collect and analyze data.

Step 1: Identified Larger Sample. First, an initial and larger sample of participants was identified through convenience sampling. This initial sample consisted of 396 COE students who dropped out during the 2013-2014 year and did not provide a specific reason for why they dropped out. For each of these students, the following data was collected: the number of courses taken before dropping out, GPA, the instructor's name, and final grades for the last two courses taken.

Step 2: MANOVA. Students were grouped into three groups based on the number of courses taken prior to dropping out; group one being 3 or less, group two being 4 to 10, and group three being 11 or more. A MANOVA was then conducted between the three groups and the following dependent variables: GPA, grade in the second-to-last course, and grade in the last course.

Step 3: Survey. An online survey consisting of 12 items was sent out to the 396 students. Survey items were multiple choice and short answer. Surveys were anonymous except for individuals who indicated a willingness to be interviewed and who included contact information in their responses.

Step 4: Interviews. The final item on the survey asked students if they would be willing to be interviewed. Of the students who indicated they were willing to be interviewed on the survey, six were selected. The selection process began with in-depth research of each student, including number of classes, grades, and any comments made that indicated their reason for dropping out. Students who had only taken a few classes and did not pass them were not selected. The examination of these students revealed they dropped for repeated class failures. Instead, students who had been successful in their classes and had completed several classes at the institution with passing grades were chosen for an interview to determine why they had dropped out. Questions asked by the researchers were specific to each student and based on answers that were provided on the survey or how that student performed in the classroom. Sample interview questions are located in Appendix A. Interviews were conducted via phone or through the exchange of emails.

Step 5: Classroom Walk-Throughs. Based on the data collected in step one, a list of "most frequently last courses taken" was created by the researchers. This list consisted of six undergraduate online courses. For each course, 10 students (60 students in total) were randomly selected (data was organized in an Excel database which allowed the researchers to use a random number generator function to select the students) and classroom walk-throughs were conducted to look for potential evidence that could have contributed to the student dropping out. Previous research carried out by Lee and Choi (2011) was used to provide guidance on what the evidence might look like. 


\section{Results}

Data was collected from university databases, an online survey, interviews, and classroom walk-throughs. Analysis of the data consisted of frequency calculations, a MANOVA, and content analysis.

\section{MANOVA}

Students were grouped in three groups based on the number of courses they had taken prior to dropping out. A MANOVA was conducted between the three groups and the following dependent variables: GPA, grade in the second to the last course, and grade in the last course. Table 1 presents the average GPAs and course grades for each group on the three variables being examined.

\begin{tabular}{|c|c|c|}
\hline Variables and Groups & $\mathrm{N}$ & $\mathrm{M}(\mathrm{SD})$ \\
\hline \multicolumn{3}{|l|}{ GPA } \\
\hline Group 1 & 111 & $2.17(1.05)$ \\
\hline Group 2 & 158 & $2.16(.789)$ \\
\hline Group 3 & 104 & $2.47(.849)$ \\
\hline
\end{tabular}

Second to Last Course

Grade

Group 1

111

48.47 (38.77)

Group 2

158

$56.02(28.27)$

Group 3

104

$54.85(26.49)$

Last Course Grade

$\begin{array}{lcc}\text { Group } 1 & 111 & 62.92(25.59) \\ \text { Group } 2 & 158 & 45.84(25.99) \\ \text { Group 3 } & 104 & 50.06(29.52)\end{array}$

Table 1. Descriptive Statistics for each Dependent Variable by Group. Note: Number of students is less than the original 396. Only students in which all three variables could be recorded were used in the MANOVA analysis.

Results from the MANOVA showed a statistically significant difference between the three groups and the three dependent variables, $\mathrm{F}(6,738)=11.19, \mathrm{p}<0.05$; Wilks $\Lambda=0.846, \eta^{2}=0.08$. Follow-up least significant difference (LSD) tests revealed specific significant differences between GPA and the last course grade. Table 2 presents the groups in which significant differences were visible. 


\begin{tabular}{cc}
\hline \multicolumn{1}{c}{ Variables and Groups } & Difference in Means \\
\hline GPA & -0.3 \\
Group 1 and Group 3 & -0.31 \\
Group 2 and Group 3 & \\
\hline Last Course Grade & 17.08 \\
Group 1 and Group 2 & 12.86 \\
Group 1 and Group 3 & \\
\hline
\end{tabular}

Table 2. Groups with Significant Differences on GPA and Last Course Grade

\section{Survey}

Eighteen participants completed the survey. Age of the participants ranged from 25 to 50 . Approximately $72 \%$ were female and $17 \%$ were male (two did not indicate gender). Approximately $28 \%$ identified themselves as Caucasian, $22 \%$ as African American, $5.5 \%$ as Asian, $5.5 \%$ as Hispanic, 5.5\% Native American, and $17 \%$ as Other (two did not indicate race). Of the 12 items on the survey, three items were of particular interest in regards to better understanding why students may have decided to drop out. These items were:

1. What were your reasons for originally enrolling at the University?

2. Please select the primary reasons for why you decided to discontinue your studies at the University.

3. Is there anything that the University, its faculty, or its staff could have done to increase the likelihood of continuing your education with the University? If so, what?

Items 1 and 2 provided for a multiple-choice response, while item 3 called for a short answer response. Table 3 summarizes the results for the first question and Table 4 summarizes the results for the second question.

\begin{tabular}{|c|c|c|}
\hline Rank & Reason & Percent Agreed \\
\hline 1 & Flexibility to complete course work on my own schedule & $72 \%$ \\
\hline 2 & $\begin{array}{l}\text { [The] University offered a degree that was aligned to my } \\
\text { career goals }\end{array}$ & $44 \%$ \\
\hline 3 & Affordable education compared to other universities & $28 \%$ \\
\hline 3 & Flexible acceptance standards & $28 \%$ \\
\hline 5 & Other: Convenience & $11 \%$ \\
\hline
\end{tabular}




\begin{tabular}{clc}
\hline Rank & \multicolumn{1}{c}{ Reason } & Percent Agreed \\
\hline 1 & I became too busy with work and/or family & $39 \%$ \\
\hline 2 & $\begin{array}{l}\text { I felt like I was not receiving the necessary support from } \\
\text { faculty and advisors }\end{array}$ & $38 \%$ \\
\hline 3 & I felt like the course material was too difficult & $28 \%$ \\
\hline 3 & I was unable to continue due to financial reasons & $28 \%$ \\
\hline 5 & I felt like I was not receiving a quality education & $22 \%$ \\
\hline 5 & $\begin{array}{l}\text { Other: Just need a break, technology issues, disability } \\
\text { worsened, misled/misplaced in program }\end{array}$ & $22 \%$ \\
\hline Table 4. & Reasons for Discontinuing Studies at the University & $\mathrm{N}=18$
\end{tabular}

In regard to the third survey question, there was one dominant theme: Support, specifically, support in four areas: Course, Financial, Staff/Institutional, and Motivational. From a course standpoint, one student said, "More support and advice on how to complete assignments properly." Another student mentioned financial concerns: "Set me up a payment option." Unhappy with the support he/she was receiving from university staff, one student stated: "Yeah, they need to LISTEN and pay attention to what the student is wanting to do for their career!!!! I am really disappointed in the counseling that I got!"

Finally, another student who wanted additional motivational support simply stated, "Motivate me more."

\section{Interviews}

Of the students who indicated a willingness to be interviewed on the survey, six were selected. Sample interview questions are located in Appendix A. Interviews were conducted via phone or through email exchange.

After speaking with one student, the researcher discovered the primary reason the student had dropped out was because he "was not getting a teaching certificate" upon graduation. This student has since enrolled in another online university that does issue teaching certificates. Another student stated:

The reason I haven't finished my education is simply because my financial aid was applied incorrectly. Normally all my classes are paid for out of my financial aid and then I'm sent any remainder. However, this last time one class was apparently not paid for. I was expected to pay for the class all of a sudden [...] I don't have money sitting around [...]

One student shared via email:

I emailed my advisor numerous of times asking to re-enroll me and he failed to do so. Therefore, I just put it on the back burner because I couldn't get reinstated. I want to finish out my degree and as soon as I can, but that is my only hold-up is getting someone to enroll me. He never called or emailed me back when I emailed him. 
This student appeared to fault the University. However, an in-depth examination of the student's work in several classes revealed him to be an interesting, articulate, and strong student who was doing great in his classes until ongoing plagiarism was detected after which he dropped out. This particular student had accommodations and made comments on the survey about accommodations issues for special needs students, but never mentioned that he may have been dropped due to plagiarism.

An additional student interviewed supported the previous comment about advisors. This student was mistakenly enrolled into an Early Childhood track and was unable to change to the Educational Studies track, finally dropping out in frustration.

Two of the interviewees were residents of American Samoa. The primary reason these two students dropped out of the program were related to the lack of technology in their location, including unreliable Internet (due in large part to weather issues), inability to access websites, and lack of access to programs and computers. These two students were interviewed by email, as if was difficult to connect via phone due to the time difference.

\section{Classroom Walk-Throughs}

Classroom walk-throughs were conducted on 60 randomly selected students. There were 55 different instructors among the courses that were reviewed. To help guide the researchers in looking for potential evidence that may have contributed to the students' dropping out, research conducted by Lee and Choi (2011) was used. According to Lee and Choi (2011) student-related factors include such elements as academic background, relevant experiences, skills, and psychological attributes. Within this sample, student-related factors such as skills (i.e. time management, juggling multiple priorities) and psychological attributes (i.e. motivation, interest in subject matter) were most frequently seen.

Specifically, the researchers looked for evidence in three categories: Student related factors, Course/Program related factors, and Environmental related factors. Of the 60 students reviewed, 51 offered potential evidence of at least one of these factors.

One student shared "I was having a very difficult time trying to make this work. I think I took on more than I could handle." With another student, it was evident he/she was not interested in the subject matter:

I don't really like psychology classes because I just don't think I get it or want to get it $[\ldots]$ This will be my third time trying to take a psychology class. I dropped out twice before in the traditional school.

A third student appeared to come into the class with a negative mindset toward using technology:

As far as technology goes. I only use if I have to, otherwise, I am old fashion. I really do not want to have to use the mic or the web cam at all. Since I need to do this for this course, I will [be] cautiously engaged. I feel this way because I am a private person and I really do not care for the online networking at all.

Course- and program-related factors, the second most frequent category of factors seen in this sample, would pertain to elements like course design, institutional support, and interactions among students and the instructor (Lee \& Choi, 2011). Knowledge of program offerings or what a program prepared a student to do after graduation was an issue. One student said, "My major at 
[the] University is Education. I am strongly considering changing my major to Education Counseling."

Deciding to change majors is common occurrence among undergraduate students, but this particular university did not offer a degree in Education Counseling. Another student stated, "My major will more than likely be changing to Cognitive Studies so I can pursue a career in Occupational Therapy or in that area."

Here one might argue that a degree in Cognitive Studies is not going to prepare a student to be an Occupational Therapist. Instructor interaction was also a potential issue. Table 5 summarizes the inconsistency/lack of instructor interaction.

\begin{tabular}{lclc}
\multicolumn{2}{c}{ Discussion Forum Interaction } & \multicolumn{2}{c}{ Feedback on Assignments } \\
\hline Level of Interaction & $\begin{array}{c}\text { \# of } \\
\text { Instructors }\end{array}$ & \multicolumn{1}{c}{ Level of Interaction } & \# of Instructors \\
\hline Doesn't carry on the discussion & 13 & $\begin{array}{l}\text { Offer a little summative } \\
\text { feedback but no in-text } \\
\text { assignment feedback }\end{array}$ & 11 \\
\hline $\begin{array}{l}\text { Doesn't address students by } \\
\text { name }\end{array}$ & 3 & $\begin{array}{l}\text { Offer no summative } \\
\text { feedback but a little in-text } \\
\text { assignment feedback }\end{array}$ & 13 \\
\hline Offers shallow responses & 2 & $\begin{array}{l}\text { Offer no feedback on } \\
\text { assignments }\end{array}$ \\
\hline
\end{tabular}

Table 5. Instructor Interaction

\section{University Data and MANOVA}

\section{Discussion}

The MANOVA conducted focused on examining the differences in academic performance between the three groups based on the number of courses taken prior to dropping out (group one being 3 or less, group two being 4 to10, and group three being 11 or more). Overall results from the MANOVA were statistically significant with specific differences being seen with GPA and the last course grade. In terms of GPA, differences were seen between groups 1 and $3(p<0.05)$ as well as between 2 and $3(\mathrm{p}<0.05)$. In each case, the mean of group 3 was higher. There was a positive trend seen which was supported with a significant and positive correlation (.18). The more courses a student took before dropping out, the higher their GPA. These results may not be too unexpected. One might conclude that if a student is taking more classes, chances are they are passing them, which in turn could translate into a higher GPA. A question that might arise is, why drop out after $10+$ courses? If students appear to have more academic success as they take more courses, then the likelihood of dropping out may not be due to academic reasons.

In terms of last course grade, differences were seen between groups 1 and $2(p<0.05)$ as well as between groups 1 and $3(\mathrm{p}<0.05)$. In each case, the mean of group 1 was higher. Overall, there was a negative trend seen with this variable, meaning, the more courses a student took before 
dropping out, the lower his/her grade was in the last course. Unlike GPA, it may be difficult to conclude whether or not these results would be expected. There could be multiple questions raised. For example, are students who took fewer courses prior to dropping out actually trying harder, but despite their effort they still struggle and decide to drop out? Do students who take more courses "run out of steam," or motivation and simply stop trying in their last course? These additional questions may indicate a need for further research.

\section{Survey}

An online survey was sent to all students identified in the initial larger group. Three survey items were of particular interest and will be discussed here:

1. Why students enrolled in the online university

2. Why students discontinued their studies

3. Whether or not there was anything the university could have done to keep the students from discontinuing their studies

The number one reason students decided to attend the online university was identified as Flexibility to complete course work on my own schedule. This rationale mirrors previous research which has found flexibility and convenience as a desirable trait of online courses among students (Barbour, 2008; Kenny, 2002; Northrup, 2002; Smart \& Cappel, 2006; Young \& Norgard, 2006). The number one reason why students discontinued their studies was, I became too busy with work and/or family. Several students who indicated flexibility as a main reason for enrolling also said they discontinued their studies because they became too busy with work and/or family. What does this mean? Although flexibility is an attractive feature and draws students to online learning, some students might misjudge their ability to juggle priorities and/or balance school with work and/or family.

Seventy-five percent of the respondents who indicated not receiving a quality education as a primary reason for discontinuing their studies, also indicated not receiving the necessary support from faculty and advisors. What can be taken from these results? Quality does not just equate to content and/or course design. There are students that take note of the level in support they receive and may factor this into what it means to receive a "quality education."

Based on survey responses, it appeared that one thing the University could have done to increase the likelihood of retaining these students was to provide more support; specifically in areas of course, financial, staff/institution, and motivation. These results are in line with some of the reasons students discontinued their studies (i.e. a lack of quality education and lack of support from faculty and advisors), as reflected in previous research that notes the importance of support in the online learning environment (Ally, 2004; Hunte, 2012; Muilenburg \& Berge, 2005). Not only did the issue of support reveal itself in the survey, but it was also brought up during the interviews, as well as in the classroom walk-throughs.

\section{Interviews}

The interviews revealed a few potential contributing factors that may have led to students to discontinue their studies. One factor was a lack of teaching certification offered by the institution. Although there are plans in progress to offer a route to teaching certification, at the time of this study, a degree from the College of Education (COE) at this online university did not lead to teaching certification. For many students this could be a critical detail. It was common to see students make statements in their introductory posts about wanting to become a teacher. Efforts 
to notify students that the degree does not lead to a teaching certificate are made in several ways (i.e. disclaimers on $\mathrm{COE}$ website and program pages). However, students may still have enrolled in the program, without a full understanding of what such disclaimers mean.

Another potential factor that revealed itself during interviews was financial reasons. This was further supported by the survey results, which showed financial reasons as a primary reason for a student's decision to discontinue studies. In addition, these results coincide with previously collected data from the university, which indicated financial reasons as being a factor that contributed to students dropping out.

The interviews revealed additional motives for dropping out. Two students from areas with poor technology infrastructure were overwhelmed by the effort it took to keep up. These students were also challenged by time zone issues and much of their struggle came from work submitted late. They have a challenging situation in American Samoa with weather and Internet access. These students would benefit from a more flexible late work policy, which the institution has recently implemented. Classroom examination of instructor comments in the gradebook showed many instructors refusing to accept work more than three days late.

Interview data also revealed the need for students to be coached in writing skills, including proper citation and paraphrasing of sources to avoid plagiarism. Instructors need to work to detect and correct plagiarism issues early in a student's program. Finally, as with other data collection methods, support appeared to be a potential factor that may affect a student's decision to drop out. There was a consistent complaint of inability to secure needed guidance from advisors and enrollment specialists. This is something that has been, and continues to be, addressed by the institution and has improved since these students dropped out.

\section{Classroom Walk-Throughs}

After conducting the classroom walk-throughs, it appeared that student factors such as time-management skills, the ability to juggle multiple priorities, and psychological attributes may have been contributing factors to students deciding to drop out of online courses. Students would often explain in their introduction posts how busy they were raising a family, working, and going to school. In addition, it was common to see students with sporadic performance (e.g. zeros throughout the gradebook for not having completed discussions and/or assignments). Such performance could be attributed to students not having the time, or not managing their time skillfully enough to complete coursework. Flexibility and/or convenience are often noted as a primary reason why students take online courses or pursue a degree online (Barbour, 2008; Kenny, 2002; Northrup, 2002; Smart \& Cappel, 2006; Young \& Norgard, 2006). However, "flexibility" does not mean "less time," "less motivation," or courses being "easier." It is reasonable to think that a student may set out to pursue a degree online thinking, "It's flexible, therefore I'll be able to easily work it into my schedule and keep up the schoolwork," only to find out that the commitment to their studies still takes time. As a result, if a student does not have strong time management skills, the ability to balance life/work/school, or maintain the motivation after a long day of work, they may struggle to keep up with their coursework.

The classroom walk-throughs also revealed potential course- and program-related factors. Examples of such factors include knowledge of program offerings, what a program prepares a student to do after graduation, and a lack of instructor interaction. In most cases, a student will pursue a specific degree because they have a specific job in mind or field of employment they want go into. Some students appeared to lack knowledge about the degrees offered by the university, 
(for example, a student wanting to switch his/her major to Education Counseling, a degree not offered by this university). Misunderstanding what a degree was meant to prepare a student to do and then realizing the misalignment could contribute to a student's decision to drop out. An example of such a misalignment may include a student pursing a degree in Cognitive Studies thinking it will prepare them to become an Occupational Therapist. If a student has a career goal and the university does not offer a degree to help achieve that career goal, it is not unlikely to think that the student would leave the university to find an institution that did offer a more suitable degree. Furthermore, many students would make statements in their introduction posts about wanting to be a teacher, work with children, etc. At the time of this study, a degree from the COE at this university did not lead to a teaching certificate, which would be needed to teach within the United States. As a result, a student might be inclined to leave the university if their goal was to become a certified teacher. This was confirmed in one of the phone interviews where the student said he/she discontinued their studies because the degree did not lead to teaching certification, and that she had enrolled at another online university which did issue teaching certifications.

Another potential course- and program-related factor was a lack of instructor interaction. The course walk-throughs revealed many instructors who were not fully engaged with students in discussion forums and/or providing meaningful feedback (or any feedback) on assignments. This lack of presence and interaction can contribute to the feeling of isolation and disconnect that is sometime noted when taking online courses. Research has shown that it is important to create a sense of social presence and community in online courses (Aragon, 2003; Rovai, 2000; Rovai, 2002). For example, when students feel part of an online community, their feelings may have a positive impact on student attitude and performance. Facebook pages, LinkedIn groups, and a chat or socialization area in the online classroom are all examples of how social presence and community can be developed in online institutions (Moore \& Fetzner, 2009). Students need to feel supported and oftentimes, the instructor is the first line of support in the online classroom. If the instructor is absent, the student may feel as if he/she is "in it alone," and believe they cannot or should not reach out to the instructor for support. The student's ability to cope with the lack of an instructor may have a negative influence on their performance and/or motivation to continue their studies. Although there were several instructors who provided little or inconsistent interaction, it is important to note that there were instructors that displayed the opposite. Sixteen instructors appeared to offer positive interaction in both the discussion forums and in assignment feedback.

\section{Limitations}

Several limitations can be noted in the study that could affect the generalization of the results. First, the population was drawn from students enrolled at an online for-profit institution as opposed to taking online courses at a traditional university that also offers face-to-face courses. Second, the students were exclusively undergraduate students who had declared themselves as Education majors. Third, the students enrolled at the institution reflect a non-traditional student population (e.g. they tend to be older in age and many face additional demands on their time such as family and work). Fourth, the researchers intended to collect more demographic data through the online survey. Due to the low response rate for the survey, this goal was not achieved. Fifth, because of the low survey response rate, a very small sample size was obtained in terms of survey and interview data. 


\section{Conclusions}

Retention in for-profit online universities is an important issue, and will continue to be a focus of many institutions. The following are some general conclusions based on the research results:

- A lack of support could be a key contributing factor to students dropping out;

- Although students are drawn to online learning for the flexibility and convenience it offers, some students may misjudge their ability to balance multiple priorities or are unaware of the time commitment that is still needed for their studies;

- It cannot be assumed that students drop out of online for-profit universities because they struggle academically;

- The likelihood of students dropping out due to poor academic performance may be higher earlier in a program (i.e. took fewer courses). However, students who drop out further along in the program (i.e. took more courses) may drop out due to factors other than poor academic performance; and

- It may be a combination of factors that lead to students dropping out of online programs.

The following recommendations may be offered based on the results:

1) Make sure college advisors have manageable student loads and are knowledgeable about all academic programs.

2) Make sure instructors are not only content experts but have a passion for teaching and are student-centric.

3) Offer additional time management and organization coaching for students with multiple priorities and/or create programs that allow for more flexible self-pacing. This adjustment would not only support students with busy schedules, but also build in time for technology or time zone related issues.

4) Design retention inventions that address factors other than academic performance as it cannot be assumed that all students drop due to poor academic performance.

5) Ensure a higher level of support for students earlier in their programs and identify students at risk of dropping out early so intervention efforts can be put into place.

This research study lends support to previous research that indicates retaining students is a complex challenge that involves many aspects of the institution (Lee \& Choi, 2011: Willging \& Johnson, 2009; Mansfield et al.,2011). Educational institutions as a whole need to be supportive of retaining students, and those who do not complete their programs need to be solicited for feedback for continuous improvement. As research on the complexity of student retention in online academic programs is continued, the potential to develop successful strategies to combat this problem increases. 


\section{References}

Ally, M. (2004). Foundations of educational theory for online learning, in: T. Anderson \& F. Elloumi (Eds) Theory and practice of online learning (pp. 3-31). Retrieved from http://cde.athabascau.ca/online book/ch1.html

Aragon, S. R. (2003). Creating social presence in online environments. New Directions for Adult and Continuing Education, 100, 57-68.

Barbour, M. K. (2008). Secondary students' perceptions of web-based learning. Quarterly Review of Distance Education, (4), 357.

Boles, E., Cass, B., Levin, C., Schroeder, R., \& Smith, S. (2010). Sustaining Students: Retention Strategies in an Online Program. Educause. Retrieved from:

http://www.educause.edu/ero/article/sustaining-students-retention-strategies-onlineprogram

Brown, M., Keppell, M., Hughes, H., Hard, N., \& Smith, L. (2013). Exploring the disconnections: Student interaction with support services upon commencement of distance education. The International Journal of the First Year in Higher Education, 4(2). 63-74. doi: 10.5204/intjfyhe.v3i2.171

Green, J. C., V. J. Caracelli, and W. F. Graham. (1989). Toward a conceptual framework for mixed-method evaluation designs. Educational Evaluation and Policy Analysis 11 (3): 255-74.

Hunte, S. (2012). First time online learners' perceptions of support services provided. Turkish Online Journal of Distance Education, 13(2), 180-197.

Kenny, A. (2002). Online learning: Enhancing nurse education?. Journal of Advanced Nursing, $38(2), 127-135$.

Lee, Y. \& Choi, J. (2011). A review of online course dropout research: implications for practice and future research. Education Tech Research Dev. 59. 593-618. doi: 10.1007/s11423$0109177-\mathrm{y}$

Levy, Y. (2004). Comparing drop-outs and persistence in e-learning courses. Computers \& Education. 48 (2007).185-204.

Mansfield, M., O’Leary, E., \& Webb, S. (2011). Retention in Higher Education: Faculty and Student Perceptions of Retention Programs and Factors Impacting Attrition Rates. A Research Report Presented to the School of Education Indiana University. South Bend. Retrieved from http://files.eric.ed.gov/fulltext/ED521416.pdf

Moore, J, \& Fetzner, M. (2009). The road to retention: A closer look at institutions that achieve high course completion rates. Journal of Asynchronous Learning Networks, 13(3).1-22. 
Muilenburg, L. Y., \& Berge, Z. L. (2005). Student barriers to online learning: A factor analytic study. Distance Education, 26(1), 29-48.

National Student Clearinghouse Research Center. (2014). REPORT: Snapshot ReportPersistence-Retention. National Student Clearinghouse. Retrieved from http://nscresearchcenter.org/snapshotreport-persistenceretention14/

Nettles, S. (2015). A picture of entering students and their progression. Report from [The] University Office of Institutional Effectiveness.

Northrup, P. T. (2002). Online learners' preferences for interaction. Quarterly Review of Distance Education, 3(2), 219-26.

O'Keefe, P. (2013). Sense of belonging: Improving student retention. College Student Journal. 47(4). 605-613.

Rovai, A. P. (2000). Building and sustaining community in asynchronous learning networks. The Internet and Higher Education, 3(4), 285-297.

Rovai, A. P. (2002). Building sense of community at a distance. The International Review of Research in Open and Distributed Learning, 3(1).

Smart, K., \& Cappel, J. (2006). Students' perceptions of online learning: A comparative study. Journal of Information Technology Education: Research, 5(1), 201-219.

Willging, P., \& Johnson, S. (2009). Factors that influence students' decision to drop out of online courses. Journal of Asynchronous Learning Networks, 13(3), 115-127. Retrieved from http://www.adesignmedia.com/OnlineResearch/factors-dropoutv8n4_willging.pdf

Young, A., \& Norgard, C. (2006). Assessing the quality of online courses from the students' perspective. The Internet and Higher Education, 9(2), 107-115. 


\section{Appendix A Sample Interview Questions}

\section{Potential Interview Questions}

1. What made you decide to enroll at [University Name]?

a. Did you consider any other institutions other than [University Name]?

2. Were you very far in your program before you decided to leave [University Name]?

a. If yes, why not finish with [University Name]?

3. You indicated enrolling in another institution and you are now pursuing a degree that is different from the one you were pursuing at [University Name]. What degree is this?

a. Does [University Name] offer this degree?

i. If no, was this a factor in leaving [University Name]?

ii. If yes, why not say with [University Name]?

b. Do you feel you're getting a better education? If so, why?

c. Without giving specific numbers, would you say you're spending more, less, or about the same in tuition?

4. You indicated enrolling in another institution and you are now pursuing a degree that is the same as you were pursuing at [University Name]. Why didn't you decide to stay with [University Name]?

a. Do you feel you're getting a better education? If so, why?

b. Without giving specific numbers, would you say you're spending more, less, or about the same in tuition?

c. Would you say the course material is more difficult, less difficult, or the same?

5. You mentioned one the reasons you decided to leave [University Name] was a lack of support from [University Name] faculty, advisors, and/or staff. How could they have supported you better?

a. Can you provide an example of when you really could have used support and it was not offered?

6. What's the one thing that [University Name] could have done to keep you enrolled?

a. Anything else? 